\title{
Citra Merk, Fitur dan Kualitas Produk dalam keputusan Pembelian Smartphone Xiaomi
}

\author{
Nurul Ikbal Alvatwa \\ Universitas Sarjanawiyata Tamansiswa \\ Ikbal.alvatwa@gmail.com \\ Muinah Fadhilah \\ Universitas Sarjanawiyata Tamansiswa \\ muinahfadhilah17@gmail.com

\section{Putri Dwi Cahyani} \\ Universitas Sarjanawiyata Tamansiswa \\ putri.dc@ustjogja.ac.id
}

\begin{abstract}
Abstrak This study aims to determine (1) the effect of brand image on purchasing decisions for Xiaomi smartphones, (2) the effect of features on purchasing decisions for Xiaomi smartphones, (3) the effect of product quality on purchasing decisions for Xiaomi smartphones, and (4) the influence of brand image, features, and product quality on purchasing decisions for Xiaomi smartphones. This research used a quantitative approach. The population in this study were consumers who used Xiaomi smartphones. The sampling technique used purposive sampling with a sample size of 112 people. The data collection method used a questionnaire. This research uses data quality test, classical assumption test, multiple linear regression analysis and hypothesis testing. The results of this study indicate that the brand image variable has a positive and significant effect on purchasing decisions. The feature variable has no effect on purchasing decisions. Product quality variables have a positive and significant effect on purchasing decisions. The variables of brand image, features, and product quality simultaneously affect purchasing decisions.
\end{abstract}

\section{Kata Kunci Citra Merek, Fitur, Kualitas Produk dan Keputusan Pembelian}

\section{PENDAHULUAN}

Pada era globalisisi ini kemajuan teknologi terus berkembang dengan pesat, dan mendorong kemajuan di bidang teknologi dan informasi, salah salah satunya adalah berkembangnya teknologi informasi menggunakan smartphone. Smartphone sekarang tidak dianggap sebagai barang yang mewah melainkan menjadi suatu alat yang sangat penting dan menjadi kebutuhan bagi manusia karena tidak hanya digunakan untuk mengirim pesan singkat dan telepon tetapi juga digunakan untuk chatting, membuka email, dan berbagai macam komunikasi melalui internet. Dari tahun ke tahun permintaan smartphone semakin meningkat, banyak produsen smartphone yang berlomba-lomba menawarkan produk smartphone dengan berbagai fitur dan kelebihan produknya agar dapat menarik minat konsumen untuk membeli. Salah satu smartphone yang sedang ramai dibicarakan adalah produk smartphone dari produsen Xiaomi. Dalam hal umur 
smartphone Xiaomi bisa dibilang masih cukup muda namun Xiaomi bisa berkembang cukup pesat dan menjadi merek smartphone yang dapat dikenal luas dan menjadi pertimbangan dalam keputusan pembelian smartphone. (Khoirunnisa, 2020)

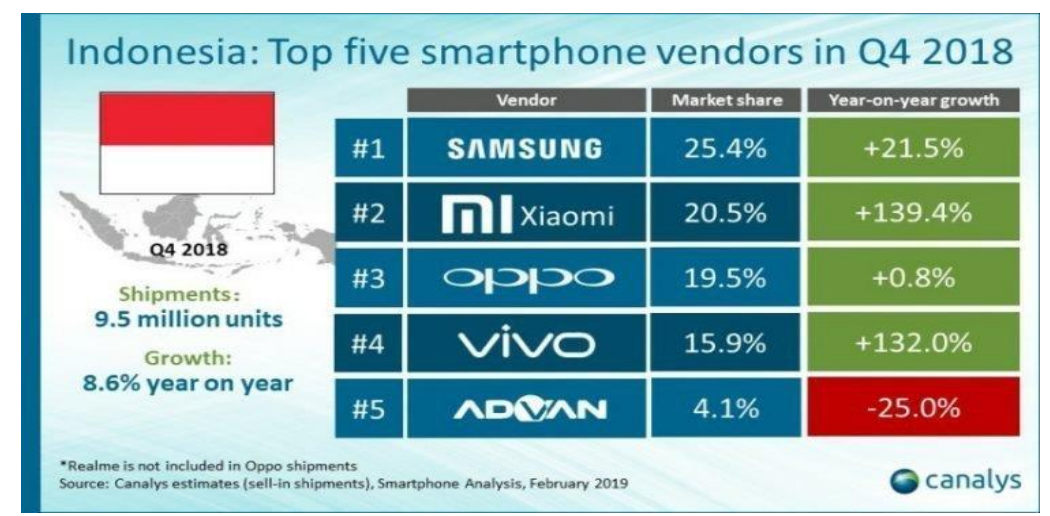

Gambar 1.1 Tren Penjualan Smartphone di Indonesia Q4 2018

Sumber : (www.canalys.com diakses 25 November 2020)

Dari data di atas Xiaomi bisa dikatakan produk smartphone yang cukup sukses dalam membuat sejarah keberhasilan hingga menjadi smartphone terlaris ke dua dipasar smartphone Indonesia pada Q4 2018. Tetapi pada Q3 2019 Xiaomi bertolak belakang dari OPPO dan Samsung, Xiaomi malah mengalami penurunan sebanyak -9\% dengan market share 19\% hingga turun menjadi posisi ketiga disusul oleh OPPO, hal tersebut dapat dilihat dari data dibawah ini:

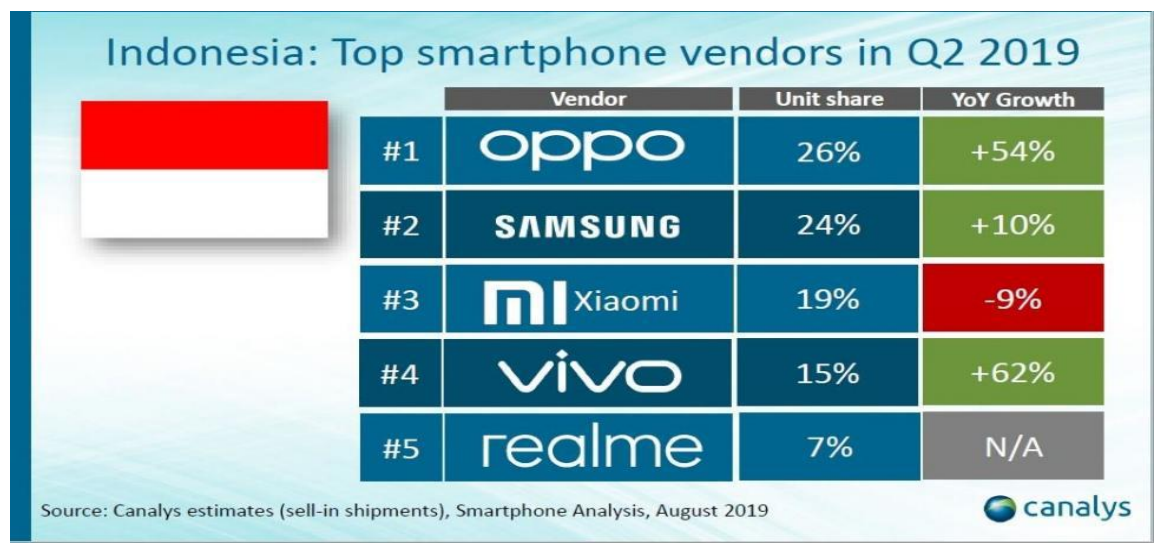

Gambar 1.2 Tren Penjualan Smartphone di Indonesia Q2 2019

Sumber : (www.selular.id diakses 18 Oktober 2020)

Dari data diatas Xiaomi turun ke peringkat ke 3, hal tersebut dikarenakan berbagai faktor internal dan eksternal dari konsumen dan para pesaing. Sekarang konsumen lebih selektif dalam melakukan keputusan pembelian termasuk dalam memilih smartphone Xiaomi. Konsumen melakukan pembelian berdasarkan berbagai unsur penilaian, salah satunya adalah citra merek. Citra merek bisa sangat bernilai, karena dapat membangun kepercayaan konsumen dan mempengaruhi keputusan pembelian (Vernando, 2018).

Selain citra merek, fitur adalah salah satu unsur yang dapat mempengaruhi minat beli konsumen dalam membeli smartphone Xiaomi. Fitur merupakan alat persaingan untuk dapat membedakan produk suatu perusahaan dengan produk sejenis yang menjadi pesaingnya (Hamidah \& Anita, 2013). Sehingga para produsen smartphone melakukan 
berbagai inovasi agar dapat membuat produk dengan berbagai fitur yang diinginkan dan dibutuhkan oleh konsumen, sehingga konsumen lebih memilih produknya dibandingkan para pesaingnya.

Dalam menentukan keputusan pembelian produk smartphone selain melihat dari segi merek dan fitur, konsumen juga membandingkan dari segi kualitas produk. Kualitas produk merupakan senjata strategis yang potensial untuk dapat mengalahkan para pesaing. Sehingga perusahaan berlomba membuat produk dengan kualitas yang paling baik, dengan kualitas produk yang paling baik tersebut perusahaan akan tumbuh dengan pesat, dalam jangka waktu yang panjang perusahaan tersebut akan lebih berhasil dibandingkan dengan perusahaan lain karena konsumen selalu menginginkan produk yang berkualitas sesuai harga yang telah konsumen bayarkan (Kotler dan Armstrong, 2008:75) dalam (Labiro, 2017).

Dari kondisi dan penjelasan yang ada, smartphone Xiaomi merupakan produk yang berkembang dengan cepat dan menjadi pilihan dalam keputusan pembelian smartphone oleh para konsumen, dalam ruang lingkup yang lebih kecil kesuksesan Xiaomi tersebut dapat terlihat dengan banyaknya mahasiswa yang menggunakan merek Xiaomi sebagai smartphone pribadi para mahasiswa. Walaupun pada Q2 2019 Xiaomi mengalami penurunan seperti pada gambar 1.2, tidak dimungkiri penurunan tersebut akibat kurangnya keputusan pembelian konsumen terhadap smartphone Xiaomi yang didasarkan pada beberapa aspek pertimbangan. Berdasarkan fenomena diatas maka dari itu peneliti akan melakukan penelitian dengan judul "Pengaruh Citra Merek, Fitur Dan Kualitas Produk Terhadap Keputusan Pembelian Smartphone Xiaomi” Studi Kasus Pada Mahasiswa.

\section{LANDASAN TEORI}

\section{Citra Merek}

Menurut Kolter dan keller (2012), citra merek atau brand image adalah presepsi yang dilakukan oleh konsumen terhadap merek suatu produk yang dibentuk dari informasi yang didapatkan melalui pengalaman menggunakan produk tersebut. Suatu citra merek yang kuat dapat memberikan keunggulan bagi produk salah satunya keunggulan dalam bersaing. Menurut Tjiptono (2011), citra merek merupakan diskripsi tentang asosiasi dan keyakinan konsumen tentang suatu merek. Asosisasi sendiri merupakan atribut yang ada pada merek dan memiliki suatu tingkatan kekuatan bagi citra merek suatu produk.

Citra merek merupakan kesan positif suatu merek produk yang ditanamkan kepada konsumen dengan mengukur citra merek sesuai kesan yang didapat konsumen. Menurut Kolter dan keller (2012) aspek yang diukur dari citra merek yaitu:
a. Kekuatan (strengthness)
b. Keunikan (uniqueness)
c. Keunggulan (favorable)

Schiffman dan Kanuk (2007) dalam Amilia (2017) Citra merek adalah sekumpulan asosiasi mengenai suatu merek yang tersimpan dalam benak atau ingatan konsumen. Ada beberapa faktor-faktor yang mempengaruhi dan pembentuk citra merek yaitu:

a. Kualitas atau mutu, berkaitan dengan kualitas produk barang yang ditawarkan oleh produsen dengan merek tertentu.

b. Dipercaya atau diandalkan. berkaitan dengan pendapat atau kesepakatan yang dibentuk oleh masyarakat tentang suatu produk yang dikonsumsi.

c. Kegunaan atau manfaat yang terkait dengan fungsi dari suatu produk barang yang bisa dimanfaatkan oleh konsumen. 
d. Harga, yang dalam hal ini berkaitan dengan tinggi rendahnya atau banyak sedikitnya jumlah uang yang dikeluarkan konsumen untuk mempengaruhi suatu produk, juga dapat mempengaruhi citra jangka panjang.

e. Citra yang dimiliki oleh merek itu sendiri, yaitu berupa pandangan, kesepakatan dan informasi yang berkaitan dengan suatu merek dari produk tertentu.

Menurut Kotler (2006) dalam Vernando (2018), citra merek adalah pengelihatan dan kepercayaan yang tertanam pada benak konsumen, sebagai cerminan asosiasi yang tertahan di ingatan konsumen. Citra merek memiliki beberapa dimensi atau indikator yaitu;

a. Fungsi merek

b. Sikap terhadap merek

c. Reputasi merek

\section{Fitur}

Fitur merupakan karakteristik tambahan yang dirancang untuk menambah ketertarikan konsumen terhadap produk atau menyempurnakan fungsi produk Dewi dan Jatra (2013). Sedangkan devinisi fitur produk menurut Fandy Tjiptono (2002) dalam Hutami dan Rahmawaty (2017) fitur adalah unsur-unsur produk yang dilihat penting oleh para konsumen dan dijadikan dasar sebagain pengambilan keputusan dalam suatu pembelian.

Menurut Hamidah dan Anita (2013) fitur merupakan alat persaingan untuk dapat membedakan produk suatu perusahaan dengan produk sejenis yang menjadi pesaingnya, sehingga menjadi alasan konsumen memilih produk perusahaan tersebut dikarenakan tidak ada pada produk para pesaingnya.

\section{Kualitas Produk}

Keputusan pembelian oleh konsumen juga tergantung pada kualitas produk yang ditawarkan, Menurut Kotler (2009) dalam Vernando (2018) produk adalah segala sesuatu yang dapat ditawarkan ke dalam pasar untuk dapat diperhatikan, dimiliki, dipakai atau dikonsumsi sehingga dapat memuaskan keinginan atau kebutuhan konsumen.

Menurut Tjiptono (2008) dalam Labiro (2017) kualitas adalah perpaduan antara sifat dan karakteristik yang menentukan sejauh mana keluaran produk dapat memenuhi kebutuhan pelanggan atau menilai sampai seberapa jauh sifat dan karakteristik itu memenuhi kebutuhannya.

\section{Keputusan Pembelian}

Menurut Kolter (2012) Keputusan pembelian adalah tahap dalam proses pengambilan keputusan dimana konsumen benar-benar membeli produk. Menurut Simamora (2002) dalam Hutami dan Rahmawaty (2017) keputusan membeli yang diambil oleh konsumen terkait 5 keputusan, yaitu:

a. Keputusan tentang jenis produk

b. Keputusan tentang bentuk produk

c. Keputusan tentang merek

d. Keputusan tentang penjualannya

e. Keputusan tentang jumlah produknya

Menurut Setiadi (2010) dalam Vernando (2018), pengambilan keputusan konsumen adalah proses pengintegrasian yang mengkombinasikan pengetahuan untuk mengevaluasi 
dua atau lebih perilaku alternative dan memilih salah satu diantaranya. Pengambilan keputusan konsumen memiliki beberapa indikator yaitu:
a. Mengenali kebutuhan
b. Pencarian informasi
c. Evaluasi alternative

\section{METODOLOGI PENELITIAN}

Penelitian ini merupakan penelitian kuantitaif. Penelitian ini dilakukan di fakultas ekonomi Universitas Sarjanawiyata Tamansiswa yang berlokasi di Jl. Kusumanegara No.121, Muja Muju, Kecamatan Umbulharjo, Kota Yogyakarta. Waktu penelitian dilakukan pada bulan Januari sampai dengan Februari 2021. Sampel dalam penelitian ini adalah mahasiswa fakultas ekonomi Universitas Sarjanawiyata Tamansiswa Yogyakarta yang menggunakan smartphone Xiaomi. Dengan menggunakan metode purposive sampling dan menggunakan rumus menurut Hair et al., (2014) dalam Bastian (2014) jumlah sampel minimal 5-10 kali jumlah indikator pertanyaan yang akan dianalisis. Dalam penelitian ini terdapat 14 indikator pertanyaan, maka jumlah sampel yang dibutuhkan adalah 14 X $8=112$ sampel. Dalam penelitian ini pengumpulan data menggunakan data primer dengan cara membagikan kuesioner. Pengukuran pengaruh variabel menggunakan uji normalitas, tes hipotesis, dll.

\section{HASIL PENELITIAN}

\section{Uji Normalitas}

1. P-Plot

Untuk menguji apakah ditribusi data normal atau tidak salah satu cara termudah yaitu dengan melihat Normal Probability Plot.

\section{Gambar 4.1 Normalitas}

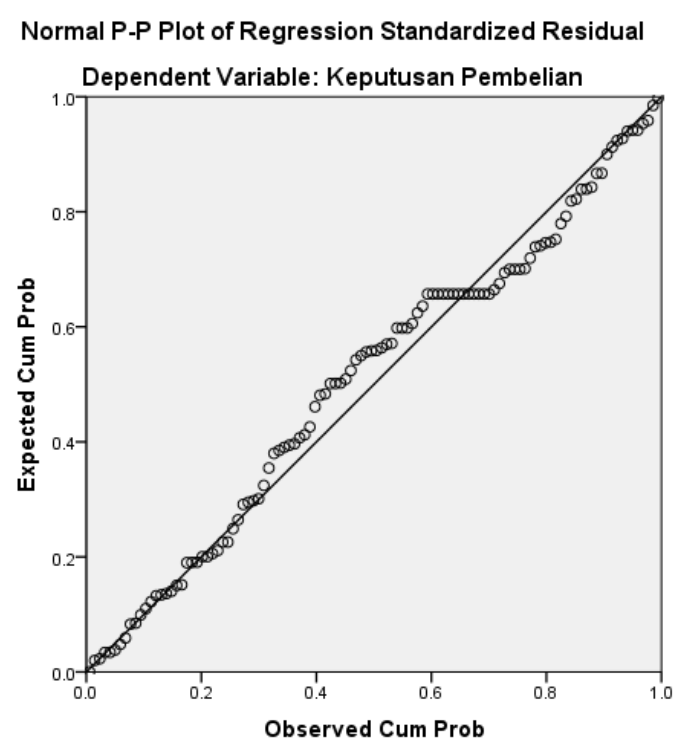

Sumber: data primer diolah, 2021

\section{Gambar 4.1 Normalitas}

Berdasarkan gambar diatas dapat diketahui bahwa penyebaran titik pada sumbu diagonal dari grafik normal P-Plot variabel citra merek, fitur, kualitas produk dan keputusan pembelian memberikan distribusi yang normal, dilihat pada 
titik-titik yang menyebar disekitar garis diagonal serta penyebarannya mengikuti arah garis.

2. Kolmogorov Smirnov

Tabel 6

Hasil Uji Normalitas

One-Sample Kolmogorov-Smirnov Test

\begin{tabular}{lll}
\hline & & Unstandardized Residual \\
\hline $\mathrm{N}$ & \multicolumn{1}{l}{ Mean } & 112 \\
\cline { 2 - 3 } Normal Parameters & & 0 \\
& Std. Deviation & 1.844115 \\
& & \\
Most Extreme Differences & Absolute & 0.082 \\
\cline { 2 - 3 } & Positive & 0.066 \\
\cline { 2 - 3 } & Negative & -0.082 \\
\hline Test Statistic & & 0.082 \\
\hline Asymp. Sig. (2-tailed) & & $.062^{\mathrm{c}}$ \\
\hline
\end{tabular}

a. Test distribution is Normal.

b. Calculated from data.

c. Lilliefors Significance Correction.

Sumber: data primer diolah, 2021

Berdasarkan tabel diatas dapat diketahui bahwa nilai Asymp.Sig (2-tailed) adalah 0,062 yang artinya lebih dari 0,05. Sehingga dapat disimpulkan bahwa data penelitian berdistribusi normal.

\section{Uji Multikolinearitas}

Uji Multikolinearitas dilakukan dengan melihat nilai Variance Inflation Factor $(V I F)$. Jika menunjukan hasil nilai VIF $<10$ dan nilai Tolerance $>0,1$ maka ditarik kesimpulan tidak terjadi multikolinearitas.

Tabel 7

Hasil Uji Multikolinearitas

Coefficients $^{\mathbf{a}}$

\begin{tabular}{|c|c|c|c|}
\hline \multicolumn{4}{|c|}{ Coeilicients ${ }^{\star}$} \\
\hline \multirow{2}{*}{\multicolumn{2}{|c|}{ Model }} & \multicolumn{2}{|c|}{ Collinearity Statistics } \\
\hline & & Tolerance & VIF \\
\hline \multirow{4}{*}{1} & (Constant) & & \\
\hline & Citra Merek & 0.344 & 2.907 \\
\hline & Fitur & 0.259 & 3.856 \\
\hline & Kualitas Produk & 0.354 & 2.822 \\
\hline
\end{tabular}

Sumber: data primer diolah, 2021. 
Berdasarkan tabel menunjukan bahwa nilai tolerance dari variabel Citra Merek yaitu 0,344, Fitur yaitu 0,259 dan Kualitas Produk yaitu 0,354. Hasil perhitungan nilai VIF pada variabel Citra Merek yaitu 2,907, Fitur yaitu 3,856 dan Kualitas Produk yaitu 2,822 yang berarti ketiga variabel menunjukan nilai tolerance lebih dari 0,1 dan nilai VIF kudarng dari 10. Maka dapat disimpulkan bahwa tidak adanya multikolinearitas antara variabel independent dalam model regresi.

\section{Uji Heterokedastisitas}

a. Uji Scatterplot

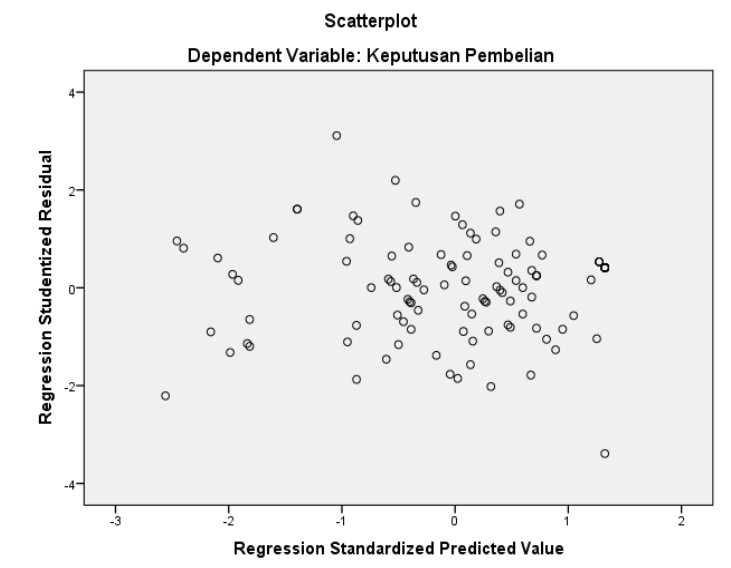

Sumber: data primer diolah, 2021.

Gambar 4.2 Hasil Uji Scatterplot

Dari grafik scatterplot diatas terlihat bahwa titik-titik menyebar secara acak dan menyebar diatas dan dibawah angka 0 pada sumbu Y. maka tidak terjadi heterokedastisitas.

b. Uji Glejser

Tabel 9

Hasil Uji Heteroskedastisitas

\begin{tabular}{|c|c|c|c|c|}
\hline \multicolumn{5}{|c|}{ Coefficients $^{a}$} \\
\hline \multirow{2}{*}{\multicolumn{2}{|c|}{ Model }} & Standardized Coefficients & \multirow[t]{2}{*}{$\mathrm{t}$} & \multirow[t]{2}{*}{ Sig. } \\
\hline & & Beta & & \\
\hline \multirow[t]{4}{*}{1} & (Constant) & & 4.246 & .000 \\
\hline & Citra Merek & -.156 & -.984 & .327 \\
\hline & Fitur & -.060 & -.329 & .742 \\
\hline & Kualitas Produk & -.046 & -.296 & .768 \\
\hline
\end{tabular}

Sumber: data primer diolah, 2021.

Hasil dari pengujian heterokedastisitas dapat dilihat dari nilai signifikan antar variabel yaitu pada variabel Citra Merek dengan nilai signifikan 0,327, variabel Fitur dengan nilai signifikan 0,742 dan variabel kualitas produk dengan nilai signifikan 0,768 . Hasil tersebut menunjukan bahwa ketiga variabel memiliki nilai signifikan lebih dari 0,05 maka dapat disimpulkan bahwa tidak terjadi heterokedastiditas.

\section{Analisis Regresi Berganda}


Tabel 10

Hasil Uji Regresi Berganda

Coefficients $^{\mathrm{a}}$

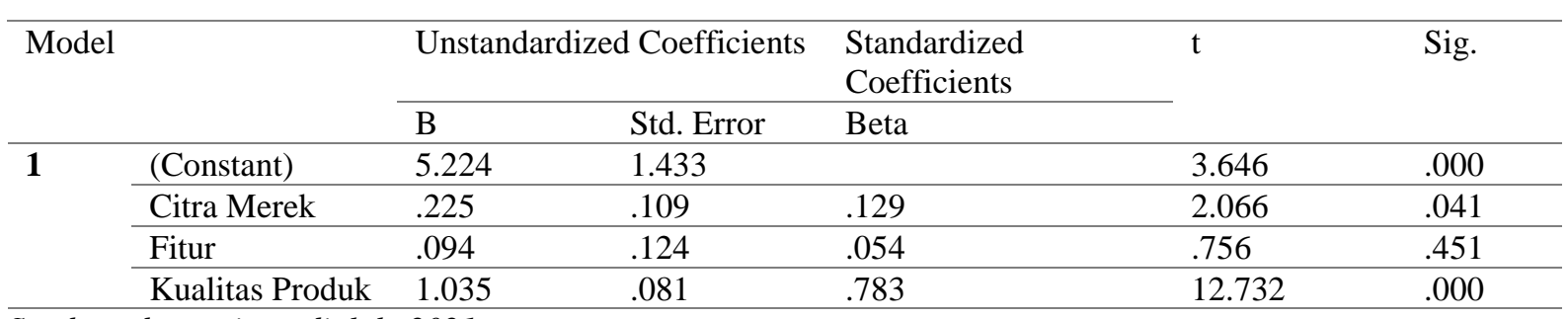

Sumber: data primer diolah, 2021

Hasil pengujian persamaan regresi diatas dapat dijelaskan sebagai berikut:

$$
\begin{aligned}
& \mathrm{Y}=\mathrm{a}+\mathrm{b} 1 \mathrm{X} 1+\mathrm{b} 2 \mathrm{X} 2+\mathrm{b} 3 \mathrm{X} 3+\mathrm{e} \\
& \mathrm{KPM}=0,129 \mathrm{CM}+0,054 \mathrm{FI}+0,783 \mathrm{KP}
\end{aligned}
$$

Keterangan:

$$
\begin{array}{ll}
\text { KPM } & =\text { Keputusan Pembelian } \\
\mathrm{CM} & =\text { Citra Merek } \\
\mathrm{FI} & =\text { Fitur } \\
\mathrm{KP} & =\text { Kualitas Produk }
\end{array}
$$

a. Persamaan tersebut menunjukan bahwa setiap penambahan atau pengurangan 1 (satu) skor citra merek akan mempengaruhi keputusan pembelian sebesar 0,129 poin apabila variabel lain diasumsikan tetap. Semakin tinggi citra merek maka semakin tinggi keputusan pembelian.

b. Setiap penambahan atau pengurangan 1 (satu) skor fitur maka akan mempengaruhi keputusan pembelian sebesar 0,054 poin apabila variabel lain diasumsikan tetap. Semakin tinggi fitur maka semakin tinggi keputusan pembelian.

c. Setiap penambahan atau pengurangan 1 (satu) skor kualitas produk maka akan mempengaruhi keputusan pembelian sebesar 0,783 poin apabila variabel lain diasumsikan tetap. Semakin tinggi kualitas produk maka semakin tinggi keputusan pembelian.

\section{Uji Hipotesis}

a. Uji t (Uji Parsial)

1. Berdasarkan uji regersi berganda diperoleh nilai t-hitung 2,066 dan nilai signifikan 0,041. Maka dari hasil tersebut menunjukan 2,066 > t-tabel 1,658 dan nilai signifikan $0,041<0,05$. Maka $\mathrm{H}_{\mathrm{a}}$ diterima dan $\mathrm{H}_{0}$ ditolak. Dapat disimpulkan bahwa citra merek (X1) berpengaruh positif dan signifikan terhadap keputusan pembelian (Y).

2. Berdasarkan uji regersi berganda diperoleh nilai t-hitung 0,756 dan nilai signifikan 0,415. Maka dari hasil tersebut menunjukan 0,756 < t-tabel 1,658 dan nilai signifikan 0,415 >0,05. Maka $\mathrm{H}_{\mathrm{a}}$ ditolak dan $\mathrm{H}_{0}$ diterima. Dapat disimpulkan bahwa fitur (X2) tidak berpengaruh dan tidak signifikan terhadap keputusan pembelian (Y).

3. Berdasarkan uji regersi berganda diperoleh nilai t-hitung 12,734 dan nilai signifikan 0,000. Maka dari hasil tersebut menunjukan 12,734 > t-tabel 1,658 dan nilai signifikan $0,000<0,05$. Maka $\mathrm{H}_{\mathrm{a}}$ diterima dan $\mathrm{H}_{0}$ ditolak. Dapat disimpulkan 
bahwa kualitas produk (X3) berpengaruh positif dan signifikan terhadap keputusan pembelian (Y).

b. Uji F

Tabel 12

Hasil Uji F

ANOVA $^{\mathrm{a}}$

\begin{tabular}{lllll}
\hline \multicolumn{2}{l}{ Model } & Mean Square & F & Sig. \\
\hline \multirow{2}{*}{1} & Regression & 743.526 & 212.726 & $\mathbf{. 0 0 0}^{\mathbf{b}}$ \\
\cline { 2 - 5 } & Residual & 3.495 & & \\
\cline { 2 - 5 } & Total & & & \\
\hline
\end{tabular}

a. Dependent Variable: Keputusan Pembelian

b. Predictors: (Constant), Kualitas Produk, Citra Merek, Fitur

Sumber: data primer diolah, 2021.

Dari hasil uji ANOVA atau F-test pada tabel diatas menunjukan nilai Fhitung sebesar 212,726 dengan signifikansi $0,000<0,05$. Dari pengujian ini dapat disimpulkan bahwa variabel citra merek, fitur dan kualitas produk secara simultan berpengaruh terhadap keputusan pembelian.

\section{Koefisien Determinasi $\mathbf{R}^{2}$}

Tabel 13

Hasil koefisien Determinasi $\mathrm{R}^{2}$

Model Summary

\begin{tabular}{|c|c|c|c|c|}
\hline Model & $\mathrm{R}$ & R Square & $\begin{array}{l}\text { Adjusted R } \\
\text { Square }\end{array}$ & $\begin{array}{l}\text { Std. Error of the } \\
\text { Estimate }\end{array}$ \\
\hline 1 & $.925^{\mathrm{a}}$ & 0.855 & 0.851 & 1.87 \\
\hline
\end{tabular}

Sumber: data primer diolah, 2021.

Pada tabel diatas menunjukan bahwa nilai koefisien determinasi atau Adjusted $R$ Square sebesar 0,851. Hal tersebut menunjukan bahwa variabel independent secara bersama-sama mempengaruhi variabel dependen sebesar $85,1 \%$ sedangkan $14,9 \%$ dipengaruhi oleh faktor lain yang tidak diteliti pada penelitan ini.

\section{KESIMPULAN}

Berdasarkan hasil penelitian yang dilakukan pada mahasiswa Fakultas Ekonomi Universitas Sarjanawiyata Tamansiswa mengenai pengaruh citra merek, fitur, dan kualitas produk terhadap keputusan pembelian smartphone Xiaomi, dapat ditarik kesimpulan bahwa Citra Merek berpengaruh positif dan signifikan terhadap Keputusan Pembelian smartphone Xiaomi. Fitur tidak berpengaruh signifikan terhadap Keputusan Pembelian smartphone Xiaomi. Kualitas Produk berpengaruh positif dan signifikan terhadap Keputusan Pembelian smartphone Xiaomi. Citra Merek, Fitur, dan Kualitas Produk secara simultan berpengaruh terhadap Keputusan Pembelian smartphone Xiaomi. Variabel independent secara bersama-sama mempengaruhi variabel dependen sebesar $85,1 \%$ sedangkan $14,9 \%$ dipengaruhi oleh faktor lain yang tidak diteliti pada penelitan ini. 


\section{DAFTAR PUSTAKA}

Alto, P. (2019). Indonesian smartphone market Q4 2018. Canalys.Com. https://www.canalys.com/newsroom/samsung-leads-in-indonesian-smartphonesas market-surges-ahead-to-close-2018-up-171

Amilia, S. (2017). Pengaruh Citra Merek, Harga, dan Kualitas Produk terhadap Keputusan Pembelian Handphone Merek Xiaomi di Kota Langsa. Jurnal Manajemen Dan Keuangan Unsam, 6(1), 660-669.

Bastian, D. A. (2014). Analisa Pengaruh Citra Merek (Brand Image) dan Kepercayaan Merek (Brand Trust) Terhadap Loyalitas Merek (Brand Loyalty) ADES PT. Ades Alfindo Putra Setia. Jurnal Strategi Pemasaran, 84, 487-492. http://ir.obihiro.ac.jp/dspace/handle/10322/3933

Dewi, A. K., \& Jatra, M. (2013). Pengaruh Atribut Produk Terhadap Keputusan Pembelian. Universitas Brawijaya.

Fazrin, A. (2019). Canalys: Top 5 Vendor Smartphone di Indonesia Q2 2019. Selular.Id. https://selular.id/2019/08/5-vendor-terbaik-di-indonesia/

Hamidah, S., \& Anita, D. (2013). Analisis Persepsi Citra Merek, Desain, Fitur Dan Pengaruhnya Terhadap Keputusan Pembelian Produk Handphone Samsung Berbasis Android (Studi Kasus Stie Pelita Indonesia). Igarss 2014, 21, 1-20.

Khoirunnisa. (2020). Geser Samsung, Xiaomi Rebut Posisi Top 3 Brand Smartphone di Indonesia. Selular.Id. https://selular.id/2020/11/geser-samsung-xiaomi-rebutposisi-top-3-brand-smartphone-di-indonesia/

Kolter, P. (2012). Manajemen Pemasaran Perspektif Asia (Pertama). Andi.

Kolter, P., \& keller, K. L. (2012). Marketing Management (14th ed.). Pearson Prestice Hall.

Labiro, M. K. (2017). Pengaruh Citra Merek,Harga Dan Kualitas Produk,Pada Keputusan Pembelianproduk Purbasari Lipstick Matte. 36.

Sari, H. P., \& Rahmawaty, P. (2017). Pengaruh Citra Merek, Fitur, Dan Persepsi Harga Terhadap Keputusan Pembelian (Studi Pada Konsumen Smartphone Xiaomi Di DIY). 65(9), 1-10. https://doi.org/10.1007/s00106-016-0261-4

Simamora, B. (2002). Panduan Riset Perilaku Konsumen. Gramedia Pustaka Utama.

Tjiptono, F. (2011). Manajemen dan Strategi Merek. Andi.

Vernando. (2018). Pengaruh citra merek, kualitas produk, dan promosi produk terhadap keputusan pembelian smartphone samsung. 